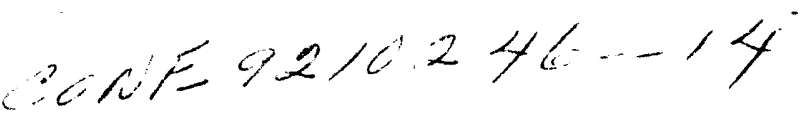

\title{
OVERVIEW OF CHARGED-PARTICLE BEAM DIAGNOSTICS FOR THE ADVANCED PHOTON SOURCE (APS)*
}

\author{
A.H. Lumpkin, G. Decker, E. Kahana, D. Patterson, \\ ANL/ASD/CP--77466 \\ W. Sellyey, A. Votaw, X. Wang, and Y. Chung \\ Argonne National Laboratory, Argonne, IL 60439 \\ DE93 007898
}

\begin{abstract}
Plans, prototypes, and initial test results for the charged-particle beam $\left(\mathrm{e}^{-}, \mathrm{e}^{+}\right)$ diagnostic systems on the injector rings, their transport lines, and the storage ring for the Advanced Photon Source (APS) are presented. The APS will be a synchrotron radiation user facility with one of the world's brightest $x$-ray sources in the $10-\mathrm{keV}$ to $100-\mathrm{keV}$ regime. Its $200-\mathrm{MeV}$ electron linac, $450-\mathrm{MeV}$ positron linac, positron accumulator ring, 7-GeV booster synchrotron, $7-\mathrm{GeV}$ storage ring, and undulator test lines will also demand the development and demonstration of key particle-beam characterization techniques over a wide range of parameter space. Some of these parameter values overlap or approach those projected for fourth generation light sources (linac-driven FELs and high brightness storage rings) as described at a recent workshop. Initial results from the diagnostics prototypes on the linac test stand operating at $45-\mathrm{MeV}$ include current monitor data, beam loss monitor data, and video digitization using VME architecture.
\end{abstract}

\section{INTRODUCTION}

The Advanced Photon Source (APS) will be a synchrotron radiation user facility with one of the world's brightest $x$-ray sources in the $10-\mathrm{keV}$ to $100-\mathrm{keV}$ regime $^{1}$. Its $200-\mathrm{MeV}$ electron linac, $450-\mathrm{MeV}$ positron linac, positron accumulator ring (PAR), 7-GeV booster synchrotron, 7-GeV storage ring, and undulator test lines will also provide the opportunity for development and demonstration of key particle beam characterization techniques over a wide range of parameter space. Some of these values overlap or approach those projected for fourth generation light sources as described at a recent workshop ${ }^{2}$. The Accelerator Systems Division (ASD) Diagnostics Group is responsible for the design, procurement, testing, and operation of all the diagnostic systems on the injector rings, their transport lines, the storage ring, and the undulator test lines. A description of these plans using electrical conversion and optical conversion techniques and initial results from some prototypes tested on the linac test stand operating at $45-\mathrm{MeV}$ are presented briefly. These are supplemented by more detailed reports given elsewhere at this workshop ${ }^{3-7}$. A brief outline of the undulator test line parameters and diagnostics are also presented.

*Work supported by the U.S. Department of Energy, Office of Basic Energy Science under Contract No. W-31-109-ENG-38.

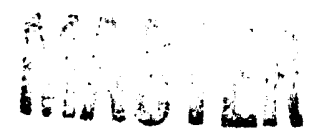




\section{BACKGROUND}

Space precludes providing a complete description of the accelerator facilities for the APS but some background information is needed. The baseline electron source is a thermionic gun followed by a $200-\mathrm{MeV}$ linac operating at a RF frequency of $2.8 \mathrm{GHz}$ and a maximum macropulse repetition rate of $60 \mathrm{~Hz}$. The base injector (gun, bunchers, and 45-MeV accelerating structure) was operated April through June 1992 as the injector linac test stand ${ }^{8}$. The design goals include 14-ps long

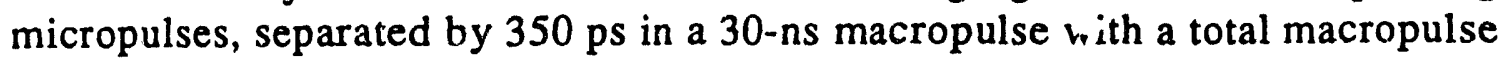
charge of $50 \mathrm{nC}$. The $200-\mathrm{MeV}$ linac beam will be focused to a 3-mm spot at the positron-production target. The target yield is about 0.0083 positrons per incident electron with a solid angle of $0.15 \mathrm{sr}$ and an energy range of $8 \pm 1.5 \mathrm{MeV}$. The positrons will then be focused by a pulsed solenoid and about $60 \%$ of them will be accelerated to $450 \mathrm{MeV}$. Commissioning of these two linacs is to be completed by December 1993. The 450-MeV positrons are injected into the horizontal phase space of the PAR at a $60-\mathrm{Hz}$ rate. As many as 24 macropulses can be accumulated as a single bunch during each 0.5 -s cycle of the injector synchrotron. The injector (or boos ier) synchrotron accelerates the positrons to $7 \mathrm{GeV}$ at which energy they can be extracted and injected into the designated RF bucket of the storage ring. Figure 1 shows a schematic of the APS accelerators and lists the number of diagnostic stations.

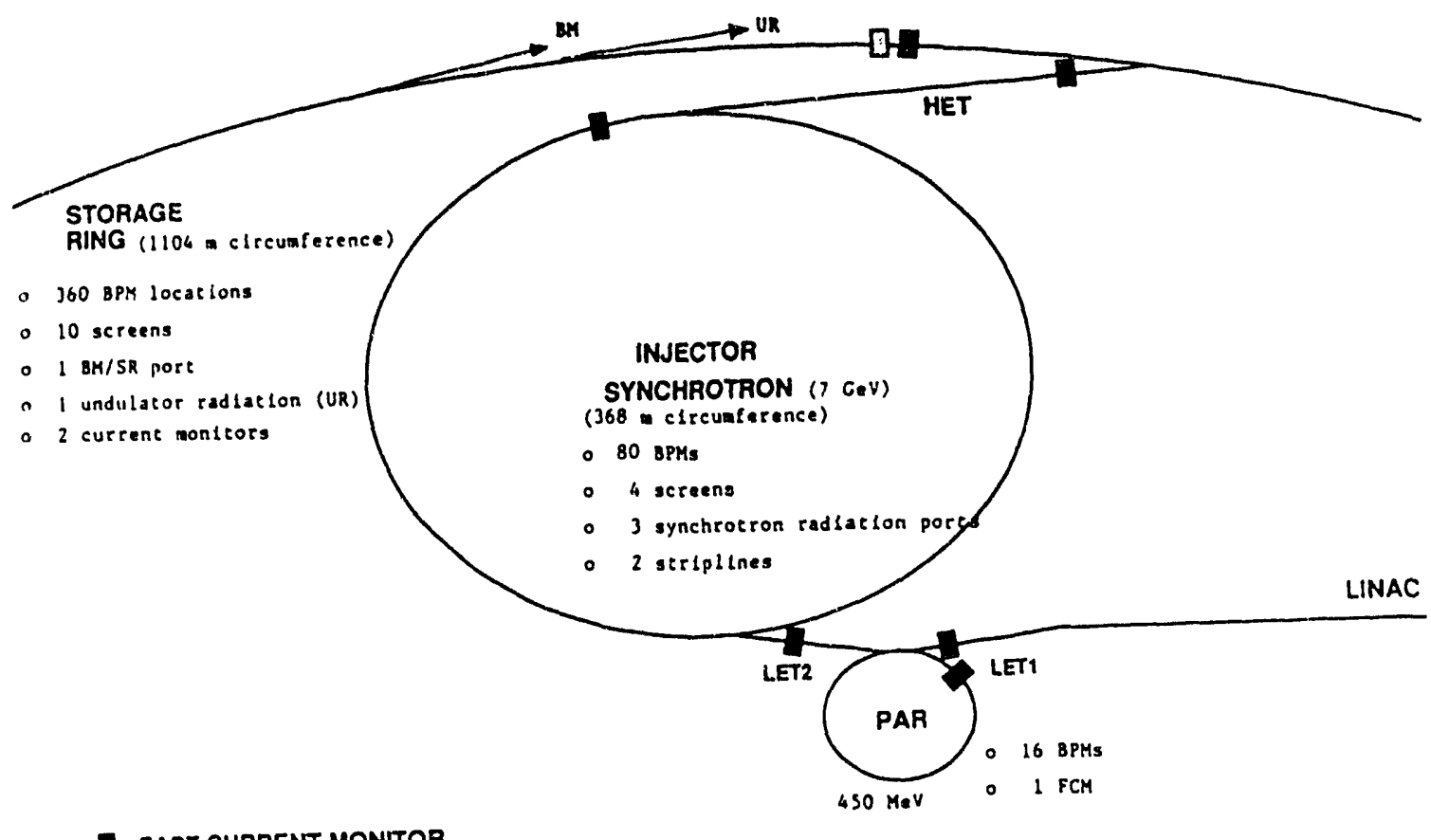

FAST CURRENT MONITOR

D DC CURRENT MONITOR

Fig. 1 A schematic layout of the APS accelerator and diagnostics. 
Several features of the subsystems are provided in Table I. The peak current, bunch length, and charge per pulse are given for the low energy transport (LET) lines between the linac and the PAR and the PAR and synchrotron, respectively. The high energy transport (HET) parameters are also provided. The revolution time, bunch length, and average currents are provided for the rings.

\section{TABLE I}

\section{APS PARAMETERS FOR BEAM DIAGNOSTICS}

\begin{tabular}{|c|c|c|c|}
\hline & LET 1 & LET 2 & HET \\
\hline PEAK CURRENT & $8 \mathrm{~mA}$ & $11.9 \mathrm{~A}$ & $28.9 \mathrm{~A}$ \\
\hline BUNCH LENGTH & $30 \mathrm{~ns}$ & $0.29 \mathrm{~ns}$ & $122 \mathrm{ps}$ \\
\hline INTENSITY PER PULSE & $1.5 \times 10^{\circ}$ postirons & $2.2 \times 10^{10}$ & $2.2 \times 10^{10}$ \\
\hline CHARGE PER PULSE & $240 \mathrm{pC}$ & $3.5 \mathrm{nC}$ & $3.5 \mathrm{nC}$ \\
\hline PULSE RATE & $60 \mathrm{~Hz}$ & $2 \mathrm{~Hz}$ & $: 4 \mathrm{z}$ \\
\hline
\end{tabular}

\begin{tabular}{|c|c|c|c|}
\hline & PAR & IS & $\mathbf{S R}$ \\
\hline RF FREQUENCY & 9.77 or $117 \mathrm{MHz}$ & $351.93 \mathrm{MHz}$ & $351.93 \mathrm{MHz}$ \\
\hline REVOLUTION TIME & $102.3 \mathrm{~ns}$ & 1.228 us & 3.68 us \\
\hline NUMBER OF BUNCHES & 1 & 1 & 1 to 60 \\
\hline MIN BUNCH SPACING & & & $20 \mathrm{~ns}$ \\
\hline BUNCH LENGTH & $30 \mathrm{~ns}<_{0.92 \mathrm{~ns}}^{0.29 \mathrm{~ns}}$ & $122 \mathrm{ps}$ & 35 to $100 \mathrm{ps}$ \\
\hline MIN AVE BEAM CURRENT & $\begin{array}{c}1.4 \mathrm{~mA} \\
\text { I inac pulse injected }\end{array}$ & & $\begin{array}{l}0.22 \mathrm{~mA} \\
\text { tor singlo bunch }\end{array}$ \\
\hline MAX AVE BEAM CURREINT & $\begin{array}{c}33.4 \mathrm{~mA} \\
26 \text { inae pulsos injectod }\end{array}$ & $4.7 \mathrm{~mA}$ & $\begin{array}{c}5 \mathrm{~mA} \\
\text { for single bunch }\end{array}$ \\
\hline MAXINTENSITY & $\begin{array}{c}3.6 \times 10^{10} \\
24 \text { in } 20 \text { julsos injoctod }\end{array}$ & $3.6 \times 10^{10}$ & $\begin{array}{l}2.2 \times 10^{10} \\
\text { ger Sunch per md }\end{array}$ \\
\hline
\end{tabular}




\section{PROCEDURES AND RESLILIS}

The basic charged-particle parameters such as ham position, profile, current, bunch length, energy, and beam loss are to be adtressed. Both intercepting and nonintercepting techniques are combined. Some of these have initial prototype results from the linac test stand this year. Some will be tested at other operating storage ring facilities around the country in the next year.

A strong component of the beam position monitoring (BPM) involves RF BPM pickup elements and their electronics. The prototype button feedthrough for the storage ring is shown in Fig. 2; over 1800 have been received and electrically tested. In addition to these, there will be intercepting beam profile screens and the use of synchrotron radiation from at least one bending magnet in each of the rings. Gated, intensified cameras will supplement standard television viewing cameras to provide individual bunch and/or single pass capability.

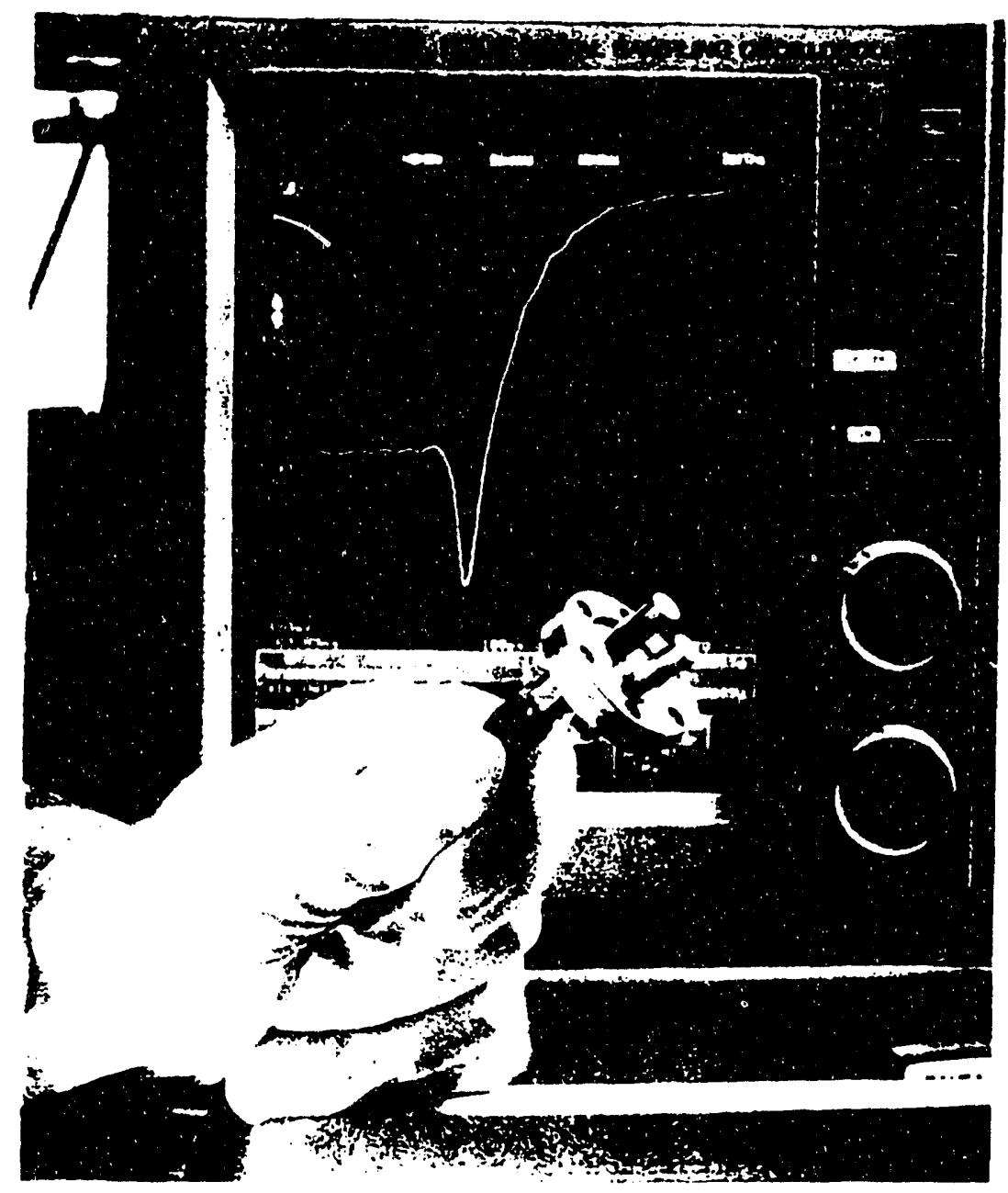

Fig. 2 Photograph of the RF bution fedthrugh for the storage ring beam position monitor. 
Because the pulse structures of the electron linac will be representative of beam in the linac-to-par transport line or LET1, the prototype current monitor system based on a fast current transformer manufactured by Bergoz and in-house electronics was tested on the linac test stand. It was installed with a shield at the end of the beamline just before a Faraday cup. Test results for a 30-ns macropulse and the $100 \mathrm{~mA}$ current level are reported in Ref. 5.

The loss monitor system which will cover the entire extent of beamlines and accelerators was tested as a prototype. A gas-filled coaxial cable acting as an ionization chamber was installed along the length of the linac test stand. Preliminary tests showed the effects of applied high voltage to the cable, gas mix, gas pressure, cable diameter, and cable impedance. The rise time of the system is less than $15 \mathrm{~ns}$ when the high voltage is set to 500 volts so axial location determination by signal arrival time analysis is under investigation. Position resolution of 7 feet or less may be practical. Sample data are shown in Ref. 6 where applied voltage polarity flips the observed signal polarity. The system also picked up a noticeable amount of noise from the RF modulator tank located a few meters away beyond the radiation shielding wall.

The imaging techniques can be applied to several aspects of the diagnostics problems. Initial tests included a VME-architecture-based video digitizing system linked to a Sun workstation. The beam image digitized was one of the first in the startup tests on the linac test stand. Background subtraction, pseudo-color intensity, pseudo-3D display, and beam profiles are demonstrated in the composite image of Fig. 3. The digitizing scheme can be applied to particle energy spectra (images from an energy-dispersive region) and particle bunch length (video readout of a streak camera). The imaging initiative also includes further evaluation of optical transition radiation (OTR) and synchrotron radiation angular distribution and polarization effects.

\section{UNDULATOR TEST LINES}

The undulator test lines are being considered at $650 \mathrm{MeV}$ and $7 \mathrm{GeV}$. In the first case, the tungsten positron conversion target will be retracted and the $450-\mathrm{MeV}$ linac rephased to accelerate the electrons to $650 \mathrm{MeV}$. A key point here would be the switch to the RF thermionic gun which is projected to provide normalized, edge emittance of about $10 \pi \mathrm{mm}$ rad, a few orders of magnitude colder than the standard thermionic gun?. This gun also may allow micropulse bunch lengths of less than $1 \mathrm{ps}$ to be attained via filtering and magnetic compression techniques. The emittance at 200 to $650 \mathrm{MeV}$ will be measured in a straight $10-\mathrm{m}$ long section that bypasses the PAR. Cross-comparison of several techniques, including three-screen, two-screen, optical transition radiation interferometry, and quadrupole field scan, is planned. Bunch length will be determined by a streak camera using either OTR ${ }^{7}$ or some other 


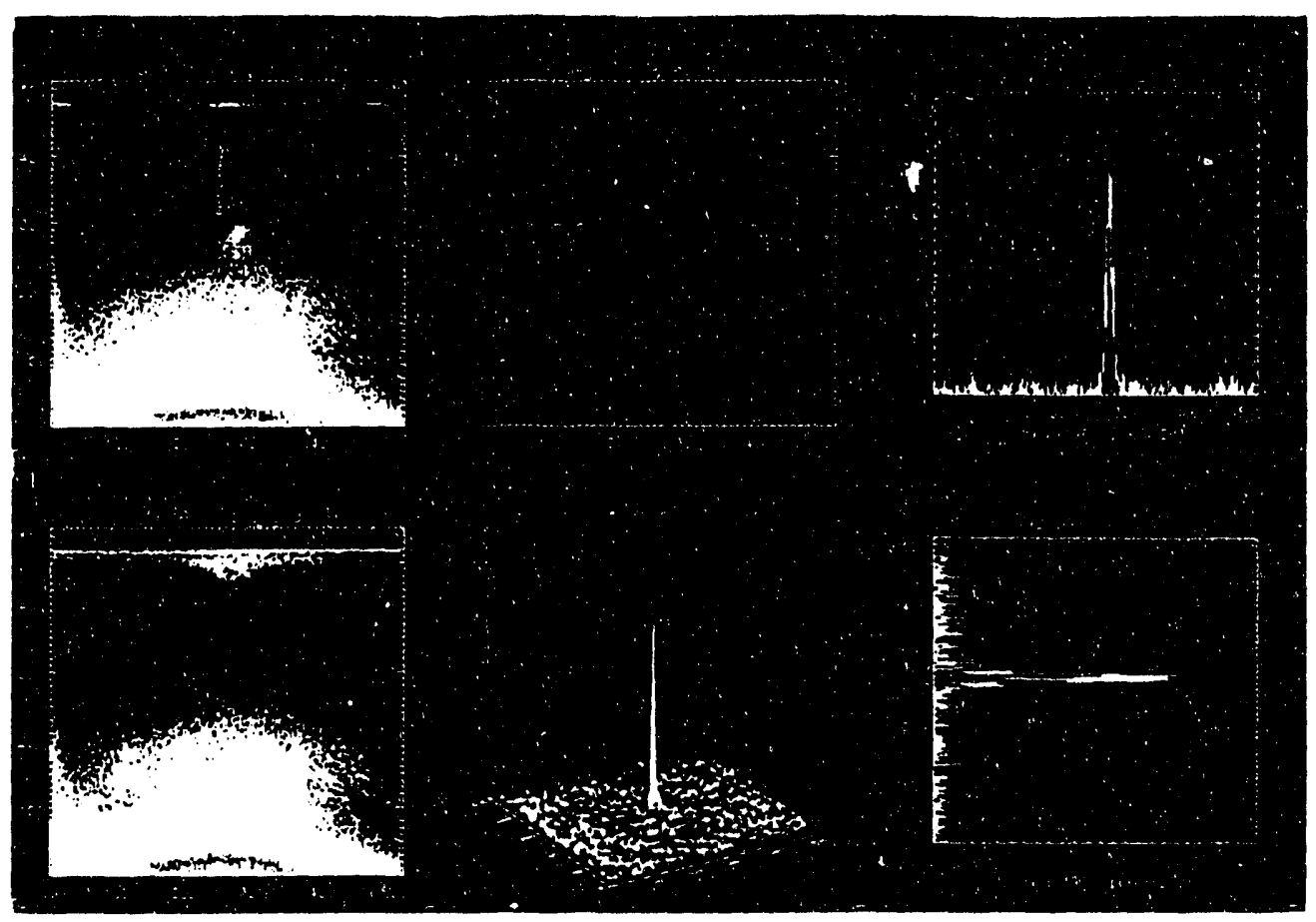

Fig. 3 Composite image of an initial beamspot recorded at a position just after the accelerator. VME-based hardware, a Sun workstation, and PV-wave display software platform were used.

prompt mechanism. As shown in Table II, many of the critical beam parameters identified in the 4th Generation Light Source Workshop ${ }^{2}$ will be approached by the proposed undulator test line $\mathrm{e}^{-}$beam.

\section{SUMMARY}

In summary, key charged particle beam parameter characterizations are being addressed at the APS. Due to the diverse parameter space involved. a number of complementary intercepting and nonintercepting beam techniques are being employed. In the rings, of course, nonintercepting techniques are dominant. The undulator test line initiative will address transport of high brightness beams to undulators at energies that happen to be of interest to the next generation of light sources. 
TABLE \| Beam parameters for the undulator test line at APS as compared to 4th Generation Workshop values (ref. 2)

\begin{tabular}{lcc}
\multicolumn{1}{c}{ Parameter } & APS & 4th Generation Workshop (Linac) \\
$\begin{array}{l}\text { Emittance (II mm mrad) } \\
\text { (rms, normalized) }\end{array}$ & 2 & 1.5 \\
Peak Current (kA) & $1 / 2$ to 1 & $\sim 1$ \\
Bunch Length (ps) & $<1$ to 15 & $100-1000$ \\
Energy (MeV) & $200-650$ & $0.05 \%$ \\
Energy Spread & $0.1 \%$ & - \\
Macropulse Bunch Length & $30 \mathrm{~ns}$ &
\end{tabular}

\section{ACKNOWLEDGMENTS}

The authors are indebted to George Mavrogenes and John Galayda for their support, to the linac test stand operations crew including Ray Fuja, Bill Berg, and Bill Wesolowski for beam time, and to Ned Arnold and Eric Ko of the Cuntrols Group for data acquisition and analysis support. 


\section{REFERENCES}

1. D.E. Moncton, E. Crosbie and G.K. Shenoy, "Overview of the Advanced Photon Source," Rev. Sci. Instrum., 60, (7), July 1989.

2. Proceedings of the Fourth Generation Light Source Workshop, Feb. 24-27, 1992, Stanford, California, SSRL 92-02.

3. E. Kahana and Y. Chung," Test Results of a Monopulse Beam Position Monitor for the Advanced Photon Source," these proceedings.

4. A. J. Votaw, "Preliminary Design of the Memory Scanner for the Advanced Photon Source," these proceedings.

5. X. Wang, "Design and Initial Tests of Beam Current Monitoring Systems for the APS Transport Lines," these proceedings.

6. D. R. Patterson, "Preliminary Design of the Beam Loss Monitor System for the Advanced Photon Source," these proceedings.

7. A. H. Lumpkin and M. D. Wilke, "Further Time-Resolved Electron-Beam Characterizations with Optical Transition Radiation," these proceedings.

8. G. Mavrogenes et al., Proceedings of the Linac Conference, Ottawa, Canada, August 24-28, 1992.

9. M. Borland, Private Communication (July 1992), APS, Argonne National Laboratory.

\section{DISCLAIMER}

This report was prepared as an account of work sponsored by an agency of the United States Government. Neither the United States Government nor any agency thereof, nor any of their employees, makes any warranty, express or implied, or assumes any legal liability or responsibility for the accuracy, completeness, or usefulness of any information, apparatus, product, or process disclosed, or represents that its use would not infringe privately owned rights. Reference herein to any specific commercial product, process, or service by trade name, trademark manufacturer, or otherwise does not necessarily constitute or imply its endorsement, recommendation, or favoring by the United States Government or any agency thereof. The views and opinions of authors expressed herein do not necessarily state or reflect those of the United States Government or any agency thereof. 

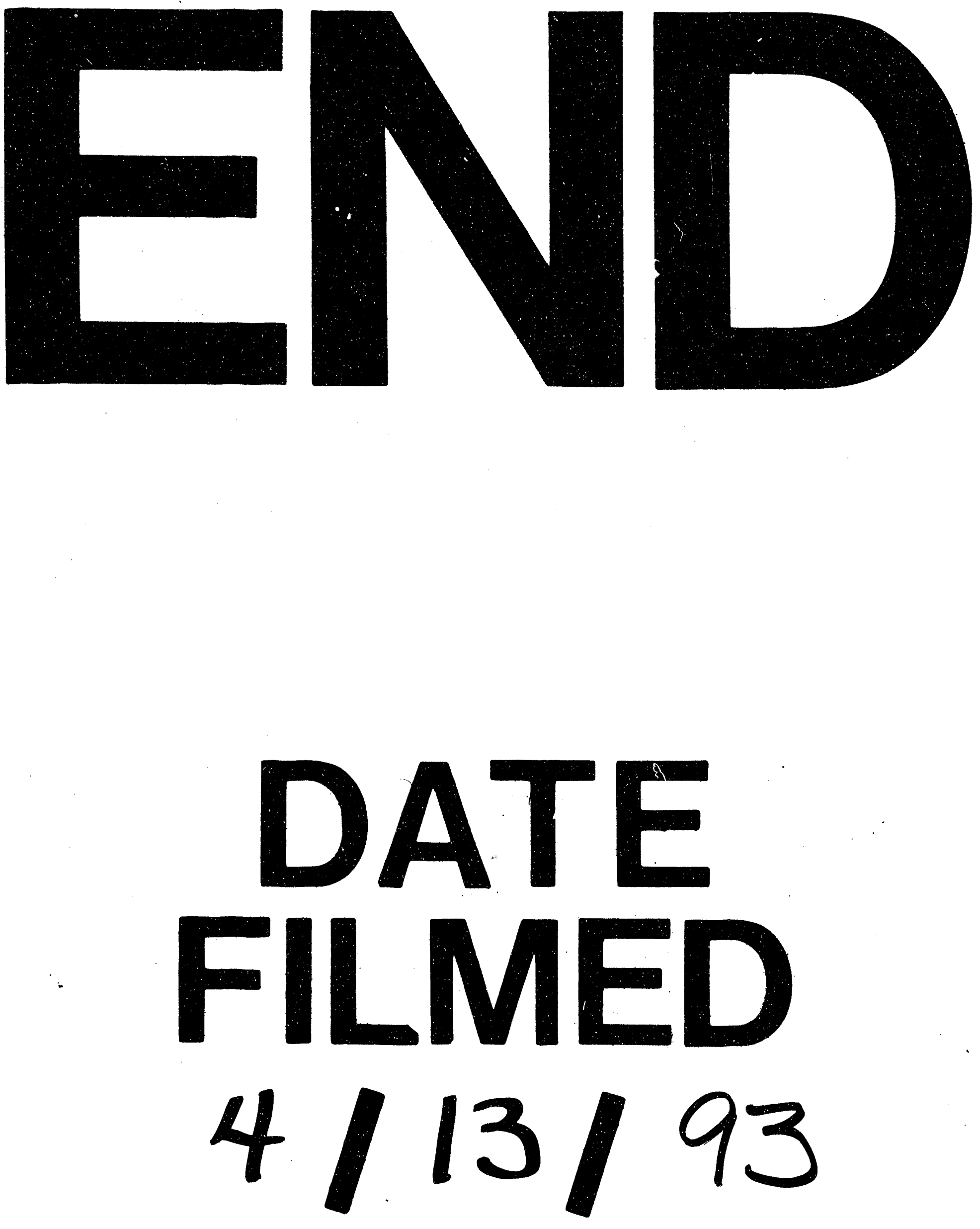
